\title{
Cuscuta arvensis Beyr "Dodder": In Vivo Hepatoprotective Effects Against Acetaminophen-Induced Hepatotoxicity in Rats
}

\author{
Ufuk Koca-Caliskan, Ismet Yilmaz, Asli Taslidere, ${ }^{3}$ Funda N. Yalcin, \\ Ceylan Aka, and Nazim Sekeroglu ${ }^{5}$ \\ ${ }^{1}$ Department of Pharmacognosy, Faculty of Pharmacy, Gazi University, Etiler-Ankara, Turkey. \\ ${ }^{2}$ Department of Pharmacology, Faculty of Pharmacy, Inonu University, Malatya, Turkey. \\ ${ }^{3}$ Department of Histology-Embryology, Faculty of Medicine, Inonu University, Malatya, Turkey. \\ ${ }^{4}$ Department of Pharmacognosy, Faculty of Pharmacy, Hacettepe University, Altindag-Ankara, Turkey. \\ ${ }^{5}$ Department of Biology, Faculty of Art and Science, Kilis 7 Aralik University, Kilis, Turkey.
}

\begin{abstract}
Cuscuta arvensis Beyr. is a parasitic plant, and commonly known as "dodder" in Europe, in the United States, and "tu si zi shu" in China. It is one of the preferred spices used in sweet and savory dishes. Also, it is used as a folk medicine for the treatment particularly of liver problems, knee pains, and physiological hepatitis, which occur notably in newborns and their mothers in the southeastern part of Turkey. The purpose of this study was to investigate the hepatoprotective effects and antioxidant activities of aqueous and methanolic extracts of $C$. arvensis Beyr. on acetaminophen (APAP)-induced acute hepatotoxicity in rats. The results were supported by subsequent histopathological studies. The hepatoprotective activity of both the aqueous and methanolic extracts at an oral dose of 125 and $250 \mathrm{mg} / \mathrm{kg}$ was investigated by observing the reduction levels or the activity of alkaline phosphatase, alkaline transaminase, aspartate aminotransferase, blood urine nitrogen, and total bilirubin content. In vivo antioxidant activity was determined by analyzing the serum superoxide dismutase, malondialdehyde, glutathione, and catalase levels. Chromatographic methods were used to isolate biologically active compounds from the extract, and spectroscopic methods were used for structure elucidation. Both the methanolic and aqueous extracts exerted noticable hepatoprotective and antioxidant effects supporting the folkloric usage of dodder. One of the bioactive compounds was kaempferol-3-O-rhamnoside, isolated and identified from the methanolic extract.
\end{abstract}

KEYWORDS: • acetaminophen $\bullet$ Cuscuta $\bullet$ hepatoprotective $\bullet$ histopathology $\bullet$ in vivo antioxidant activity

\section{INTRODUCTION}

H EPATOTOXICITY IS A LEADING CAUSE of lack of continuation of a drug therapy. Research on hepatotoxicity suggests that reactive metabolites or xenobiotics, excessive alcohol consumption, environmental, and some disease conditions are responsible for moderate to severe liver injury. Compounds causing hepatotoxicity directly affect the mitochondrial respiratory chain, also, the permeability transitional pore, cytochromes P-450, glutathione (GSH) $\mathrm{S}$-acyltransferases, and other antioxidant mechanisms in living organisms. ${ }^{1}$

Several plant extracts and polyherbal medications have been clinically approved for their effective hepatoprotective

Manuscript received 3 November 2017. Revision accepted 22 January 2018.

Address correspondence to: Ufuk Koca-Caliskan, PhD, Department of Pharmacognosy, Faculty of Pharmacy, Gazi University, Tac Street, Etiler-Ankara 06330, Emniyet District, Turkey,E-mail: ukoca@gazi.edu.tr

(C)Ufuk Koca-Caliskan et al., 2018; Published by Mary Ann Liebert, Inc. This Open Access article is distributed under the terms of the Creative Commons License (http:// creativecommons.org/licenses/by/4.0), which permits unrestricted use, distribution, and reproduction in any medium, provided the original work is properly cited. activity. ${ }^{2}$ Dodder has been consumed as a herbal tea and medicinal plant in different parts of the world. Antioxidant activity of dodder, which is used as a Turkish folk medicine to alleviate jaundice in newborn infants, suggests that it may be pharmacologically effective on the liver and against liver toxicity. Pharmacological studies have revealed that Cuscuta sp. (Convolvulaceae) have antiaging, anticancer, antihypertensive, anti-inflammatory, antiosteoporotic, antioxidant, hepatoprotective, immunomodulatory, immunostimulant, and memory enhancing activities. ${ }^{3-13}$ Although the phytochemical content of Cuscuta sp. differs according to plant variation, to date, flavonoids, polysaccharides, alkaloids, and lignans have been isolated from different Cuscuta sp. ${ }^{14}$ However, there appears to be no phytochemical or biological activity studies reported on Cuscuta arvensis Beyr. until now.

In this study, both aqueous and methanolic extracts of $C$. arvensis were applied to acute hepatotoxicity-induced animals dosed with acetaminophen. Some biochemical parameters (aspartate aminotransferase [AST], alkaline phosphatase [ALP], alkaline transaminase [ALT], blood urine nitrogen [BUN], and total bilirubin [TB]) and liver tissues of the rats were analyzed with histopathological methods to observe the 
hepatoprotective effects of the extracts on the liver tissue. This work then led to phytochemical, chromatographic, and spectral methods to isolate and identify the major and effective compound/s of the extract.

\section{MATERIALS AND METHODS}

\section{Chemicals}

Acetaminophen was purchased from Sigma Aldrich (St. Louis, MO, USA). Solvents were obtained from Merck in HPLC grade.

\section{Plant material and preparation of the extracts}

The whole flowering plant materials were collected during May 2011 at the Mardin region of Turkey. A prepared herbarium specimen was identified by Prof. Nazim Sekeroglu and the specimens (KHB-78) were deposited at the Department of Biology in Kilis 7 Aralik University, Turkey.

The dodder plant samples were powdered and divided into $400 \mathrm{~g}$ samples, which were then extracted separately with either methanol $(4 \times 1000 \mathrm{~mL})$ or water $(4 \times 1000 \mathrm{~mL})$. The methanolic extract was evaporated until dryness, whereas the aqueous extract was evaporated first, then freeze dried in a lyophilizer. The yields of methanolic extract and aqueous extract were $14.95 \%$ and $8.50 \%$, respectively.

\section{Test animals}

Seventy Sprague-Dawley female rats $(247 \pm 15.3 \mathrm{~g})$ were purchased from the Experimental Animal Research and Production Center of Inonu University, (Malatya, Turkey). They were housed on a $12 \mathrm{~h}$ light-dark cycle at $21^{\circ} \mathrm{C} \pm 2^{\circ} \mathrm{C}$, and in a relative humidity of $53 \% \pm 3 \%$. Animals were fed on standard diet pellets (normal chow) and water (tap water). The animal study protocol (No. 2011/A-94) was approved by the Ethical Committee, Faculty of Medicine, Inonu University. ${ }^{2}$ The rats were divided into six groups, as follows:
Group I (CONTROL) was fed with normal chow and tap water ad libitum $(n=7)$.

Group II (APAP) received a $850 \mathrm{mg} / \mathrm{kg}$ single acute toxic dose acetaminophen solution given by gastric gavage $(n=7)$.

Group III received $850 \mathrm{mg} / \mathrm{kg}$ single dose acetaminophen, and in addition either $125 \mathrm{mg} / \mathrm{kg}$ methanolic or aqueous extract of dodder solution was given by gastric gavage for 6 days $(n=7)$.

Group IV was given $850 \mathrm{mg} / \mathrm{kg}$ single dose acetaminophen, in addition $250 \mathrm{mg} / \mathrm{kg}$ methanolic or aqueous extract of dodder solution was given by gastric gavage for 6 days $(n=7)$.

Group V was given $125 \mathrm{mg} / \mathrm{kg}$ methanolic or aqueous extract of dodder solution by gastric gavage for 7 days $(n=7)$

Group VI was given $250 \mathrm{mg} / \mathrm{kg}$ methanolic or aqueous extract of dodder solution by gastric gavage for 7 days $(n=7)$.

During the study periods, no toxic or adverse effects or death were observed in any of the animals.

\section{Measurement of liver functions}

After day 7, the animals were sacrificed under kethamine+xylazine anesthesia. Blood, liver, and renal tissue samples were taken from all the animals. Blood samples were centrifuged at $3000 \mathrm{~g}$ for $10 \mathrm{~min}$. to obtain serum samples that were stored at $-20^{\circ} \mathrm{C}$ until analyzed. Liver tissue was immediately washed with saline and frozen at $-40^{\circ} \mathrm{C}$ until needed for the study. Liver TB and other liver function markers AST, ALT, and ALP were measured (Table 1). In vivo antioxidant activity was determined by measuring and analyzing the serum superoxide dismutase (SOD), catalase (CAT), glutathione peroxidase (GPx), and malondialdehyde (MDA) by Abbott clinical autoanalyzer (Abbott Diagnostics; Abbott Park, IL, USA) using an ion-selective electrode method (Architect c16000).

Table 1. Results of Blood Urea Nitrogen, Total Bilirubin, Aspartate Aminotransferase, Alkaline Transaminase, and Alkaline Phosphatase Parameters of the Control and Only APAP, APAP+Extracts (APAP+Aq, APAP+Cus), and only Extracts (Cus-Aq, Cus-MeOH) Given Rat Groups

\begin{tabular}{|c|c|c|c|c|c|}
\hline \multirow[b]{2}{*}{ Groups } & \multicolumn{5}{|c|}{ Parameters } \\
\hline & $B U N(m g / d L)$ & $T B(m g / d L)$ & $A S T(U / L)$ & $A L T(U / L)$ & $A L P(U / L)$ \\
\hline Control & $19.4 \pm 2.4(16-24)$ & $0.7 \pm 0.4$ & $188 \pm 67.5(89-266)$ & $67 \pm 22.1(42-99)$ & $190 \pm 54.9(128-296)$ \\
\hline APAP & $19.9 \pm 2.3(16-22)$ & $0.8 \pm 0.3$ & $232 \pm 57.2(175-329)$ & $113 \pm 28.2(85-169)$ & $201 \pm 29.4(172-243)$ \\
\hline $\mathrm{APAP}+125-\mathrm{Aq}$ & $23.3 \pm 2.1(21-27)$ & $0.6 \pm 0.4$ & $204 \pm 100.9(81-388)$ & $116 \pm 97.9(35-320)$ & $163 \pm 73.2(55-254)$ \\
\hline APAP $+250-A q$ & $21.4 \pm 3.6(15-26)$ & $0.6 \pm 0.4$ & $168 \pm 60.5(69-264)$ & $94 \pm 66.8(30-236)$ & $152 \pm 43.7(85-203)$ \\
\hline $\mathrm{APAP}+125-\mathrm{MeOH}$ & $17.9 \pm 2.7(14-22)^{b}$ & $0.7 \pm 0.4$ & $113 \pm 27.6(76-161)$ & $42 \pm 7.8(33-55)^{\mathrm{a}}$ & $125 \pm 39.6(54-171)$ \\
\hline $\mathrm{APAP}+250-\mathrm{MeOH}$ & $17.6 \pm 2.1(15-20)^{b}$ & $0.6 \pm 0.4$ & $141 \pm 23.0(116-168)$ & $48 \pm 7.1(35-56)^{a}$ & $175 \pm 41.6(111-242)$ \\
\hline CUST $125-A q$ & $19.0 \pm 2.6(16-22)$ & $0.8 \pm 0.3$ & $174 \pm 75.8(109-307)$ & $81 \pm 52.2(43-191)$ & $185 \pm 52.7(117-274)$ \\
\hline CUST 250-Aq & $18.1 \pm 2.9(15-22)$ & $0.9 \pm 0.0$ & $162 \pm 54.7(106-271)$ & $57 \pm 17.5(27-74)$ & $141 \pm 28.8(106-192)$ \\
\hline CUST $125-\mathrm{MeOH}$ & $21.1 \pm 1.5(20-24)$ & $0.5 \pm 0.4$ & $188 \pm 96.1(98-380)$ & $69 \pm 25.9(40-120)$ & $161 \pm 40.5(108-214)$ \\
\hline CUST $250-\mathrm{MeOH}$ & $19.9 \pm 2.9(14-23)$ & $0.3 \pm 0.4$ & $241 \pm 88.2(82-542)$ & $77 \pm 48.2(31-170)$ & $186 \pm 62.9(110-282)$ \\
\hline
\end{tabular}

a,b Express the statistical significance of the values.

ALP, alkaline phosphatase; ALT, alkaline transaminase; AST, aspartate aminotransferase; BUN, blood urine nitrogen; TB, total bilirubin. 


\section{Biochemical analysis}

The samples were homogenized in ice-cold 0.1 M Tris$\mathrm{HCl}$ buffer ( $\mathrm{pH}$ 7.5) (containing protease inhibitor, phenylmethylsulfonyl fluoride, $1 \mathrm{mM}$ ) with a homogenizer at $11,448 g$ for $2 \mathrm{~min}$ at $+(4-8)^{\circ} \mathrm{C}$. The homogenates were used to measure the levels of MDA, GSH, SOD, and CAT.

\section{MDA and GSH assay}

MDA, referred to as thiobarbituric acid reactive substances (TBARS), was measured with tiobarbituric acid at 535 and $520 \mathrm{~nm}$ in a spectrophotometer as previously described. ${ }^{15}$ Results were reported as nmol/g wet tissue. Reduced GSH concentrations in the homogenates were measured according to the previously described spectrophotometric method. ${ }^{16}$

\section{SOD assay}

SOD activity was measured by determining the reduction of nitroblue tetrazolium by the superoxide anion produced with xanthine and xanthine oxidase. ${ }^{17}$ One unit of SOD was defined as the amount of protein that inhibits the rate of nitro blue tetrazolium (NBT) reduction by $50 \%$ and the results are reported as units per milligram (U/mg) protein. The specific activity of the enzymes is expressed in units per miligram protein. Proteins in the seminal fluid were determined by the method of Lowry et al. ${ }^{18}$ Peroxidase activity was measured by monitoring the oxidation of reduced nicotinamide-adenine dinucleotide phosphate at $340 \mathrm{~nm}$, as described by Paglia and Valentine, and the results are reported as units per gram protein using an extinction coefficient of $6.22 \times 10^{-6} / \mathrm{M} / \mathrm{cm}^{19}$

\section{Determination of CAT activity}

CAT activity was measured according to Aebi's method, by determining the rate constant $\mathrm{k}$ (dimension: $\mathrm{s}-1, \mathrm{k}$ ) of $\mathrm{H}_{2} \mathrm{O}_{2}$ (initial concentration $10 \mathrm{mM}$ ) at $240 \mathrm{~nm}$ by the spec- trophotometer. Activity was reported as $\mathrm{k}$ (constant rate) per gram (U/g) protein. ${ }^{20}$

\section{Statistical analysis}

Statistical analysis was performed using SPSS 15 program. All data are reported as mean values \pm standard deviations. A value of $(P<.05)$ was considered as significant.

\section{Histological examination}

Liver slices were fixed with $10 \%$ formalin in phosphatebuffered saline for $24 \mathrm{~h}$ and embedded in paraffin. Sections of $4 \mu \mathrm{m}$ thickness were stained with hematoxylin-eosin $(\mathrm{H}-\mathrm{E})$ and were analyzed under the microscope to observe histopathological changes in the liver. Pictures of each slide were taken at $100 \times$ magnification.

For the light microscopical evaluation, liver samples were fixed in $10 \%$ formalin and were processed by routine tissue techniques, then they were embedded in paraffin. Paraffinembedded specimens were cut into 5-mm thick sections, mounted on slides, and stained with H-E. Sections were examined under a Leica DFC280 light microscope combined with Leica Q Win Image Analysis System (Leica Micros Imaging Solutions Ltd., Cambridge, United Kingdom).

An overall score of liver damage severity was semiquantitively assessed as follows: eosinophilic stained and pyknotic nuclei cells, necrosis, hemorrhage, and mononuclear cell infiltration. The microscopic score of each tissue was calculated as the sum of the scores given to each criterion and scored as follows: 0, none; 1, mild; 2, moderate; 3, severe.

Statistical analyses were made using an SPSS 13 and MedCalc program. All groups were compared by the nonparametric Kruskal-Wallis test. Exact $P$-values were given where available, and $P<.0001$ was accepted as statistically significant. All results are expressed as means \pm standard error.

Table 2. Results of Serum Superoxide Dismutase, Malondialdehyde, Glutathione, Catalase, and Parameters of the Control, Only APAP, APAP+Extracts (APAP+Aq, APAP+Cus), and Only Extracts (Cus-Aq, Cus-MeOH) Given Rat Groups

\begin{tabular}{|c|c|c|c|c|}
\hline \multirow[b]{2}{*}{ Groups } & \multicolumn{4}{|c|}{ Parameters } \\
\hline & $S O D(U / g$ protein $)$ & $M D A(n m o l / g)$ & GSH (nmol/g) & $C A T(K / g$ protein $)$ \\
\hline Control & $52.9 \pm 8.4(43-646)$ & $582.6 \pm 132.4(429-814)$ & $1223.4 \pm 134(1026-1468)$ & $34.3 \pm 3.1(30-37)$ \\
\hline APAP & $58.4 \pm 13(40-75)$ & $732.4 \pm 96.6(429-814)$ & $909.1 \pm 158(674-1088)^{\mathrm{djf}}$ & $28.2 \pm 4.7(22-36)$ \\
\hline APAP + 125-Aq & $23.9 \pm 9.2(17-36)^{\mathrm{hfgi}}$ & $732.4 \pm 96.6(600-905)$ & $899.4 \pm 34.6(846-955)^{\mathrm{djf}}$ & $30.6 \pm 4.6(24-36)$ \\
\hline APAP + 250-Aq & $51.1 \pm 6.5(43-60)$ & $603 \pm 92.2(506-717)$ & $1445.1 \pm 255.8(1154-1795)$ & $31.7 \pm 3.3(27-37)$ \\
\hline APAP +125-MeOH & $46.7 \pm 8.6(34-60)$ & $658.6 \pm 81(556-781)$ & $993.7 \pm 116.3(827-1154)^{\mathrm{f}}$ & $32 \pm 3.1(31-39)$ \\
\hline APAP +250-MeOH & $61.9 \pm 18.7(35-83)$ & $553.3 \pm 51.6(502-626)$ & $1736.3 \pm 165.9(1487-1897)^{\mathrm{djf}}$ & $34.7 \pm 3.7(31-39)$ \\
\hline CUST 125-Aq & $66.2 \pm 12.7(49-82)$ & $712.0 \pm 47.7(636-775)$ & $931.4 \pm 82.5(800-1053)^{\mathrm{djf}}$ & $32.3 \pm 2.5(28-35)$ \\
\hline CUST 250-Aq & $59.2 \pm 6.4(53-70)$ & $584.9 \pm 44(539-653)$ & $1088 \pm 61.3(981-1167)$ & $32.2 \pm 3.7(27-36)$ \\
\hline CUST $125-\mathrm{MeOH}$ & $68.3 \pm 8.3(57-76)$ & $540.8 \pm 63.7(432-620)^{\mathrm{gc}}$ & $916.0 \pm 69.4(809-996)^{\mathrm{djf}}$ & $31.4 \pm 1.7(30-35)$ \\
\hline CUST 250-MeOH & $52.4 \pm 8.2(42-62)$ & $655.6 \pm 85.9(429-905)$ & $1491.7 \pm 213.4(1205-1840)$ & $29.6 \pm 12.3(2-38)$ \\
\hline
\end{tabular}

Kruskal-Wallis test was used to compare the groups. The results are tabled as showing both SD and (min.-max).

Superscript letters express statistical significance.

CAT, catalase; GSH, glutathione; MDA, malondialdehyde; SOD, superoxide dismutase. 


\section{Isolation and determination of major/effective compound/s}

The methanolic extract ( $40 \mathrm{~g}$; yield: $20.67 \%)$ was dissolved in water $(100 \mathrm{~mL})$ and was first submitted to a polyamide column and eluted with a solvent gradient of $\mathrm{MeOH}-\mathrm{H}_{2} \mathrm{O}(0: 100 \rightarrow 100: 0)$ to afford nine main fractions (Frs. A-I, $200 \mathrm{~mL}$ each). All of the fractions were rich in sugars and flavonoids. The major flavonoid was isolated from fraction E (160 mg), using a Sephadex LH20 column chromatography eluting with chloroformmethanol (1:1) to give six fractions (Frs. $\mathrm{E}_{1-6}$ ). Fr $\mathrm{E}_{2}$ was subjected to preparative TLC analysis for further purification to yield $1(5 \mathrm{mg})$.

Structure elucidation of $\mathbf{1}$ was determined by NMR and mass spectrometry. ${ }^{21-23}$
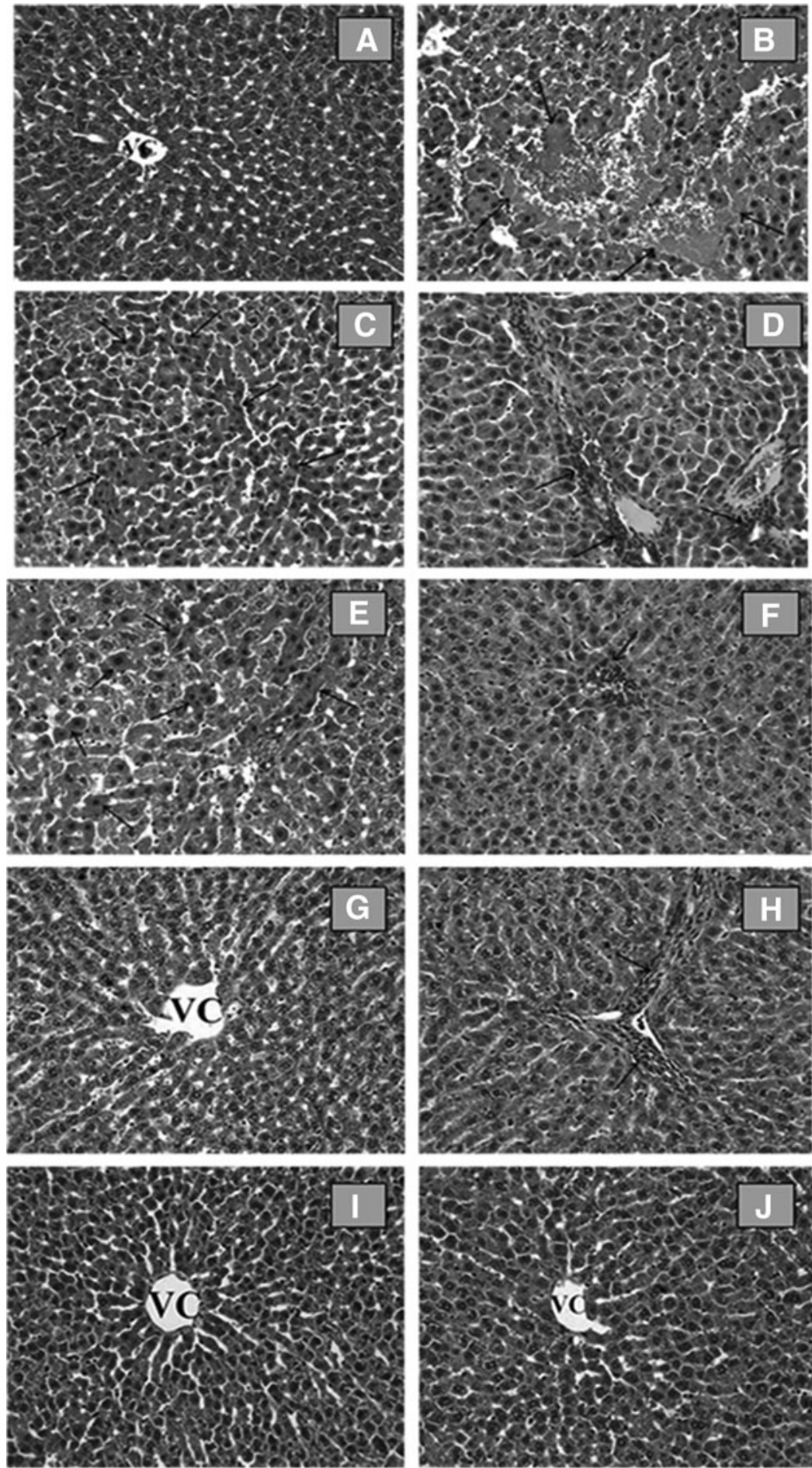
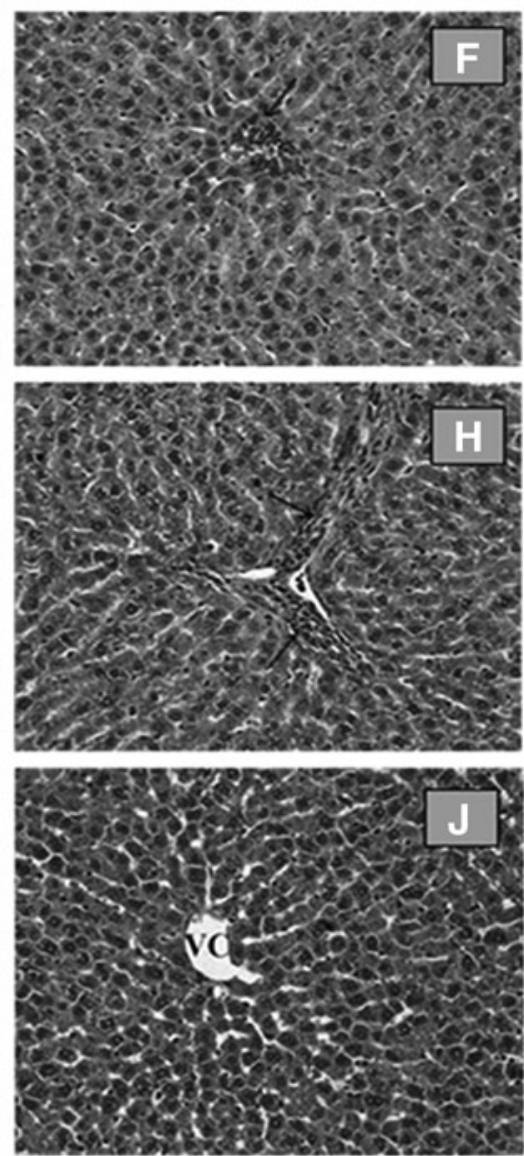

FIG. 1. (A) Control group. Normal histological appearance of liver. VC: Vena centralis. H-E; $\times 20$ : (B-D) APAP group, (B) necrosis and hemorrhage (arrows), (C) eosinophilic stained and pyknotic nuclei hepatocytes (arrows), (D) mononuclear cell infiltration (arrows). $\mathrm{H}-\mathrm{E} ; \times 20$ : APAP $+125-\mathrm{MeOH},(\mathbf{E})$ decrease of eosinophilic stained and pyknotic nuclei cells (arrows) and mononuclear cell infiltration (arrows), (F) APAP $+250-\mathrm{MeOH},(\mathbf{G})$ decrease of hemorrhage and mononuclear cell infiltration (arrows), (H) H-E; $\times 20$ : CUST 125-MeOH, (I) CUST250-MeOH, (J) groups. Liver tissue shows normal histological appearance. H-E; $\times 20$. $\mathrm{H}-\mathrm{E}$, hematoxylin-eosin. 


\section{RESULTS}

\section{Measurement of liver functions}

Plasma levels of BUN, TB, AST, ALT, and ALP were determined as measures of liver function in rats (Table 1). Only groups (CUST-MeOH, Cus-Aq) given extracts had similar results to the control group. The data have shown that only extract-given groups without any toxic drug neither had toxicity on kidney nor on liver (Table 1). Plasma levels of BUN significantly increased in the APAP intoxicated group, whereas in the Cuscuta extract groups the levels went back to the control (19.4 \pm 2.4$)$ levels. A similar pattern was observed with the TB levels, APAP $(0.8 \pm 0.3)$ caused a drastic increase, and with treatment of the Cuscuta extract with APAP or without APAP, the TB level went back to control levels $(0.7 \pm 0.4)$. Administration of APAP induced severe hepatic injury, as shown by increases in AST (232 \pm 57.2$)$, ALT $(113 \pm 28.2)$, and ALP $(201 \pm 29.4)$ enzyme levels $(P<.01)$. Treatment with Cuscuta mostly with methanolic extracts of Cuscuta (APAP +125MeOH: AST 113 \pm 27.6 , ALT $42 \pm 7.8$, ALP 125 \pm 39.6 ; APAP $+250 \mathrm{MeOH}$ : AST $141 \pm 23.0$, ALT $48 \pm 7.1$, ALP $175 \pm 41.6)$ significantly reduced plasma levels of those enzyme levels in a dose-dependent manner $(P<.05$ or .01). The recovery from APAP-induced toxicity produced by treatment with Cuscuta was similar to that seen in the control AST $(188 \pm 67.5)$, ALT $(67 \pm 22.1)$, and ALP $(190 \pm 54.9)$ (Table 1).

\section{Biochemical analysis}

The lipid peroxidation was examined by determining MDA content in liver tissue homogenate. The MDA content in the APAP group (732.2 \pm 96.6$)$ was significantly higher than that in the control group (582.6 \pm 132.4$)$. In the Cuscuta-treated groups, mostly with the methanolic extract (APAP $+250 \mathrm{MeOH}$ $553.3 \pm 51.6$ ), the MDA level decreased compared with the APAP group showing an indication of recovery from intoxication.

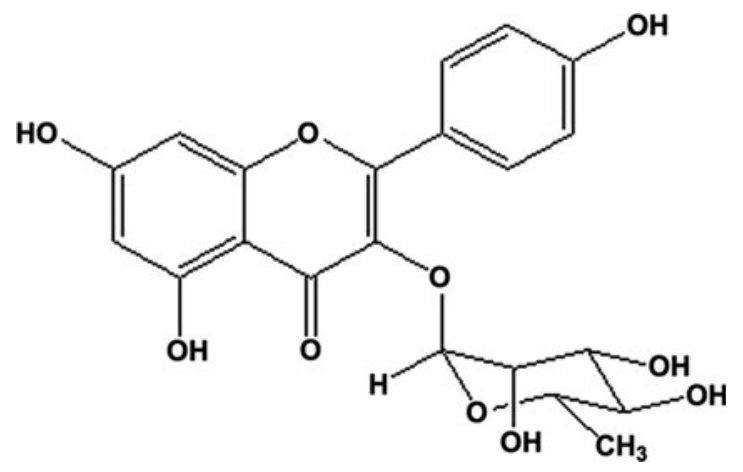

FIG. 2. Kaempferol-3-O-rhamnoside.

The levels of GSH, CAT, and SOD were determined in liver tissues. Constant levels of GSH components were found in the Cuscuta-treated groups (APAP $+125 \mathrm{MeOH}$ : 993.7 \pm 116.3 : APAP $+250 \mathrm{MeOH}: 1736.3 \pm 165.9)$ compared with the APAP group $(P<.01)$ (Table 2). Interestingly, APAP and aqueous Cuscuta-treated group (APAP +125Aq: $899.4 \pm 34.6$ ) and only aqueous Cuscuta (CUST 125Aq: $931.4 \pm 82.5$ ) given group have shown an increase in GSH levels. Cuscuta treatment significantly prevented inhibition of SOD and CAT activity caused by APAP toxicity compared with the APAP group $(P<.01)$ (Table 2$)$.

\section{Histological examination}

In the control group (Fig. 1A), and in the 125 and $250 \mathrm{mg}$ Cuscuta extract applied groups (Fig. 1E-J), the liver demonstrated a normal histological appearance. In these groups, hepatocytes showed a normal histological appearance. Sinusoids and central vein were also clearly visible.

The livers in the APAP-intoxicated group (Fig. 1B-D) revealed severe histological alterations such as centrilobular necrosis and hemorrhage, eosinophilic stained and pyknotic nuclei cells, and mononuclear cell infiltration. Normal radial

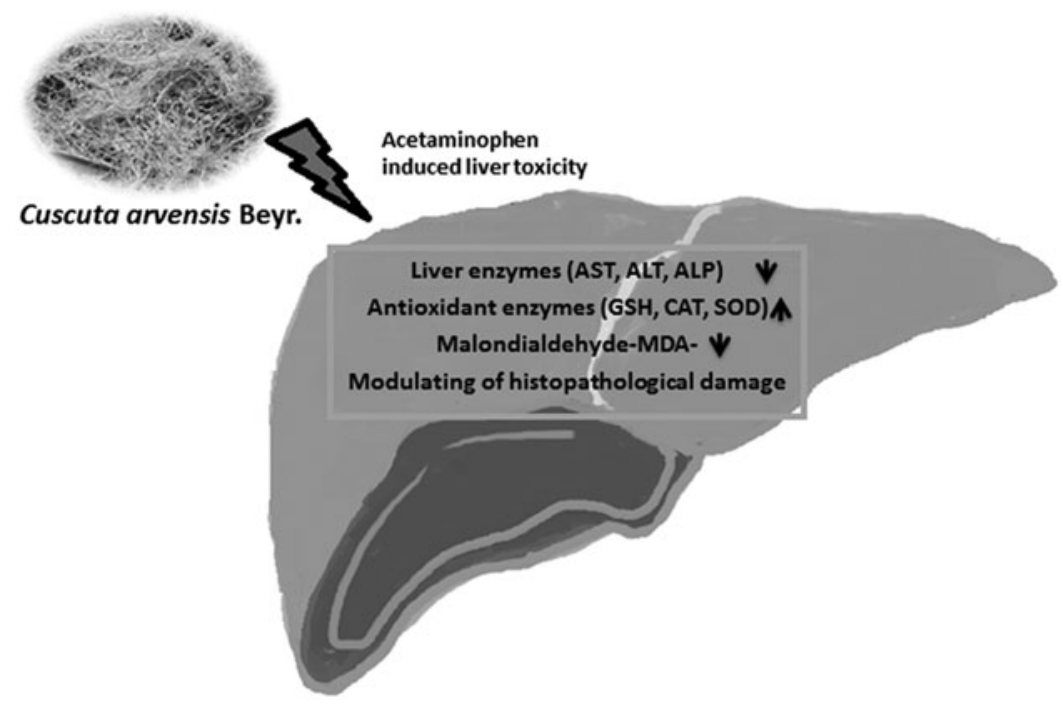

FIG. 3. Effect mechanism of Cuscuta arvensis. 
arrangements of hepatocytes from central vein were disrupted. Some of the hepatocytes in eosinophilic and in some of the hepatocytes cytoplasmic density are increased.

Eosinophilic hepatocytes in APAP $+125 \mathrm{MeOH}$ and in APAP $+250 \mathrm{MeOH}$ cuscuta groups were also observed, but these cells were not as widespread as in the APAP groups. These cells were decreased in these groups. Moreover, necrosis, hemorrhage, and mononuclear cell infiltration were decreased in APAP $+125 \mathrm{MeOH}$ and in $\mathrm{APAP}+250 \mathrm{MeOH}$ groups. In contrast, the aqueous extracts (APAP $+125 \mathrm{Aq}$, APAP +250Aq) did not improve the histopathological changes from APAP-induced hepatotoxicity in rats.

\section{Determination of the major compound}

Analysis of liver enzymes and plasma levels of biochemical parameters indicates that methanolic extracts of Cuscuta have better hepatoprotective activity than the aqueous extracts. Therefore, the methanolic extract was further fractionated and one compound was isolated and identified as 3,4',5,7-tetrahydroxyflavone-3- $O$-rhamnoside (kaempferol-3-O-rhamnoside), compound 1, on the basis of direct comparison of its spectroscopic (UV, IR, ${ }^{1} \mathrm{H}$ NMR, and mass) data with those published in the literature (Fig. 2). The most abundant flavonoid in the mixture was separated (5/ $160 \mathrm{mg}$ total fraction), with the aim of further analysis since that might be the effective compound in the raw extract.

\section{DISCUSSION}

This study demonstrated that the Sprague-Dawley rats (when APAP was administered intraperitoneally) were able to recover from hepatotoxic symptoms successfully. The extract significantly decreased the liver enzymes AST, ALT, and ALP levels and biochemical parameters BUN and TB in a dose-dependent manner in APAP intoxicated rats. Moreover, this extract increased antioxidant enzyme (GSH, CAT, and SOD) levels and decreased MDA levels, which is an indication of the recovery from lipid peroxidation in APAP hepatotoxicity-induced rats. Histopathological observations also confirmed that the methanolic extract-treated group prevented/recovered the histopathological changes caused by APAP intoxication such as centrilobular necrosis and infiltrating lymphocytes.

APAP, analgesic and antipyretic drug, is nontoxic at therapeutic doses; it is detoxified with the GSH conjugation. At toxic doses of APAP, GSH is depleted with the conjugation reaction of metabolites, in further covalent binding correlated with development of toxicity. ${ }^{24} \mathrm{GSH}$ is the major nonenzymatic antioxidant and regulator of intracellular redox homeostasis in all cell types. ${ }^{25,26}$ GSH depletion can increase the formation of reactive oxygen species (ROS) and reactive nitrogen species (RNS) such as superoxide anion, hydroxyl radical, and hydrogen peroxide and nitro oxide. Additional levels of ROS and RNS can attack biological molecules such as DNA, protein, which leads to lipid peroxidation, and depletion of the antioxidant enzymes that later cause severe oxidative stress, DNA strand breaks, apoptosis, and necrosis. ${ }^{27-29}$ The measurements of GSH were in high levels when the extracts were given in both APAP-intoxicated rats and also solely extracts given rats. The mechanism of hepatoprotection by $C$. arvensis might be due to restoration of GSH. SOD catalyzes the dismutation of superoxide anion to $\mathrm{H}_{2} \mathrm{O}_{2}$ and $\mathrm{O}_{2}$; in further CAT and GPx, there is catalysis and the decomposition of $\mathrm{H}_{2} \mathrm{O}_{2}$ to water. ${ }^{30}$ Thus, the coordinate actions of various antioxidants are critical for effectively scavenging free radicals in mammalian cells. Hepatotoxic chemicals reduce the antioxidant capacity of the liver by decreasing the activity of the antioxidant enzymes. However, Cuscuta extracts prevent the reduction of antioxidant enzymes, which consequently damage the liver. Moreover, the methanolic extract of $C$. arvensis improved liver function by decreasing the serum ALT, AST, and ALP levels in hepatotoxic rats. AST is mostly related to heart and ALT is more specific to liver; therefore, in hepatotoxication, the ALT level is expected to be increased (Fig. 3). In addition, TB, which is a byproduct of the breakdown of red blood cells in the liver, is also an indicator of the liver function. Elevation of bilirubin levels reveals damage to the liver and bile duct that cause jaundice. Methanolic extract of $C$. arvensis (APAP+MeOH) declined TB levels in treated rats, indicating that it has not only a hepatoprotective effect but also enhances the liver functional efficiency. That result also suggests scientific evidence for, and confirms the folkloric usage of $C$. arvensis, which is given to the mother as well as baby (just a few drops/ day) by infusion or maceration to alleviate jaundice in the newborn. A previous study on hepatoprotective effect of ethanolic C. chinensis extract in APAP-induced hepatoxicity showed increase in antioxidant enzyme's activities (SOD, CAT, and GPx), which is in line with our results. ${ }^{31}$ When the only extract given experiment groups were compared with the control group, the extract group had no negative effect on the kidney and liver and did not show toxicity overall in animals. Kaempferol 3-O-rutinoside and kaempferol 3-Oglucoside are known to have liver protective effects. ${ }^{32} \mathrm{~A}$ further exploration of whether the bioactive molecule kaempferol-3-O-rhamnoside (kaempferol glycosides derivative from flavonoids) responsible for the activity is under investigation in our laboratory. Since plant-originated pharmaceutical products especially for liver protection are limited in the market, demand of phytotherapeutic products supports further investigation on Cuscuta species.

\section{ACKNOWLEDGMENTS}

The authors express genuine thanks for the financial support provided by the Gazi University Scientific Research Projects Unit, with the project number 02/2012-03.

\section{AUTHOR DISCLOSURE STATEMENT}

No competing financial interests exist.

\section{REFERENCES}

1. Ko JW, Park SH, Shin NR, et al.: Protective effect and mechanism of action of diallyl disulfide against acetaminophen-induced acute hepatotoxicity. Food Chem Toxicol 2017;109:28-37. 
2. Yen FL, Wu TH, Lin LT, Cham TM, Lin CC: Nanoparticles formulation of Cuscuta chinensis prevents acetaminophen-induced hepatotoxicity in rats. Food Chem Toxicol 2008;46:1771-1777.

3. Ao L, Pan ZG, He CD: Effect of two herbs aqueous extract on the immune function of tumor-bearing mice. Yunnan J Tradit Chin Med Mater Med 2014;3:031.

4. Gao JM, Li R, Zhang L, et al:: Cuscuta chinensis seeds water extraction protecting murine osteoblastic MC3T3-E1 cells against tertiary butyl hydroperoxide induced injury. $J$ Ethnopharmacol 2013;148:587-595.

5. Jafari E, Bahmanzadegan A, Ghanbarian G, Rowshan V: Antioxidant activity and total phenolic content from aerial parts of three Cuscuta species. Anal Chem Lett 2015;5:377-384.

6. Jafarian A, Ghannadi A, Mohebi B: Cytotoxic effects of chloroform and hydroalcoholic extracts of aerial parts of Cuscuta chinensis and Cuscuta epithymum on Hela, HT29 and MDA-MB468 tumor cells. Res Pharm Sci 2014;9:115.

7. Katiyar NS, Singh AP, Gangwar AK, Rao NV: Evaluation of hepatoprotective activity of stem extracts of Cuscuta reflexa (Roxb) in rats. Int J Pharm Pharm Sci 2015;7:231-234.

8. Koca U, Kupeli-Akkol E, Sekeroglu N: Evaluation of in vivo and in vitro biological activities of different extracts from Cuscuta arvensis Beyr. (Convolvulaceae). Nat Prod Commun 2011;6:1-5.

9. Lan H, Du SM: Study on the Anti-aging action of the extracts of Cuscuta chinensis in natural aging mice. China Pharm 2010;39: 3667-3669.

10. Moon M, Jeong HU, Choi JG, et al.: Memory-enhancing effects of Cuscuta japonica Choisy via enhancement of adult hippocampal neurogenesis in mice. Behav Brain Res 2016;311:173-182.

11. Sohn DW, Kim HY, Kim SD, et al.: Elevation of intracavernous pressure and NO-cGMP activity by a new herbal formula in penile tissues of spontaneous hypertensive male rats. J Ethnopharmacol 2008;120:176-180.

12. Sekeroglu N, Koca U, Meraler SA: Geleneksel Bir Halk İlac1: İkşut. [A Traditional Folk Medicine: İkşut]. J Agric Sci 2012;22: 235-243.

13. Udavant PB, Satyanarayana SV, Upasani CD: Preliminary screening of Cuscuta reflexa stems for anti inflammatory and cytotoxic activity. Asian Pac J Trop Biomed 2012;2:1303-1307.

14. Yen FL, Wu TH, Lin LT, Cham TM, Lin CC: Concordance between antioxidant activities and flavonol contents in different extracts and fractions of Cuscuta chinensis. Food Chem 2008; 108:455-462.

15. Uchiyama M, Mihara M: Determination of malonaldehyde precursor in tissues by thiobarbituric acid test. Anal Biochem 1978; $86: 271-278$.
16. Ellman M: A spectrophotometric method for determination of reduced glutathione in tissues. Anal Biochem 1959;74:214-226.

17. Sun Y, Oberly LW, Li Y: A simple method for clinical assay of SOD. Clin Chem 1988;34:479-500.

18. Lowry O, Rosenbraugh N, Farr L, Rondell R: Protein measurement with the folin-phenol reagent. J Biol Chem 1951;183: 265-275.

19. Paglia DE, Valentine WN: Studies on the qualitative characterization of erythrocyte glutathione peroxidase. J Lab Clin Med 1967;70:158-163.

20. Aebi H: Catalase in vitro. Methods Enzymol 1984;105:121-126.

21. Löffler C, Czygan FC, Proksch P: Phenolic constituents as taxonomic markers in the genus Cuscuta (Cuscutaceae). Biochem Syst Ecol 1997;25:297-303.

22. Tripathi VJ, Yadav SB, Upadhyay AK: A new flavanone, reflexin, from Cuscuta reflexa and its selective sensing of nitric oxide. Appl Biochem Biotechnol 2005;127:63-67.

23. Wang Z, Fang JN, Ge DL, Li XY: Chemical characterization and immunological activities of an acidic polysaccharide isolated from the seeds of Cuscuta chinensis Lam. Acta Pharmacol Sin 1999;21:1136-1140.

24. James LP, Mayeux PR, Hinson JA: Acetaminophen-induced hepatotoxicity. Drug Metab Dispos 2003;31:1499-1506.

25. Balaban YH, Aka C, Koca U: Liver immunology and herbal treatment. World J Hepatol 2017;9:757-770.

26. Meister AMEA, Anderson ME: Glutathione. Annu Rev Biochem 1983;52:711-760.

27. Hinson JA, Bucci TJ, Irwin LK, Michael SL, Mayeux PR: Effect of inhibitors of nitric oxide synthase on acetaminophen-induced hepatotoxicity in mice. Nitric Oxide 2002;6:160-167.

28. Hinson JA, Reid AB, McCullough SS, James LP: Acetaminophen-induced hepatotoxicity: Role of metabolic activation, reactive oxygen/nitrogen species, and mitochondrial permeability transition. Drug Metab Rev 2004;36:805-822.

29. Michael SL, Pumford NR, Mayeux PR, Niesman MR, Hinson JA: Pretreatment of mice with macrophage inactivators decreases acetaminophen hepatotoxicity and the formation of reactive oxygen and nitrogen species. Hepatology 1999;30:186-195.

30. Hayes JD, Flanagan JU, Jowsey IR: Glutathione transferases. Annu Rev Pharmacol Toxicol 2005;45:51-88.

31. Yen FL, Wu TH, Lin LT, Lin CC: Hepatoprotective and antioxidant effects of Cuscuta chinensis against acetaminophen-induced hepatotoxicity in rats. J Ethnopharmacol 2007;111:123-128.

32. Wang Y, Tang C, Zhang H: Hepatoprotective effects of kaempferol 3-O-rutinoside and kaempferol 3-O-glucoside from Carthamus tinctorius $\mathrm{L}$. on $\mathrm{CCl}_{4}$-induced oxidative liver injury in mice. J Food Drug Anal 2015;23:310-317. 